\title{
Endoscopic closure of duodenal perforation with an over-the-scope clip during endoscopic ultrasound-guided cholangiopancreatography
}

\author{
Silvia Salord ${ }^{1}$, Joan B. Gornals ${ }^{1}$, Sandra Maisterra ${ }^{1}$, Carles Pons ${ }^{1}$, Juli Busquets ${ }^{2}$ and Joan Fabregat ${ }^{2}$ \\ ${ }^{I}$ Endoscopy Unit. Department of Digestive Diseases. ${ }^{2}$ Department of Surgery. Hospital Universitari \\ de Bellvitge-IDIBELL. L'Hospitalet de Llobregat, Barcelona. Spain
}

\section{INTRODUCTION}

Duodenal perforations are a rare complication during interventional endoscopy. Their mortality is high, and the treatment in most cases is surgical.

We report a case of duodenal perforation (type I, Stapfer) (1) during an interventional endoscopic ultrasound (EUS) procedure resolved using an over-the-scope clip called OTSC®.

\section{CASE REPORT}

A 74-year-old woman presented obstructive jaundice. Computed tomography revealed a pancreatic head tumor with dilatation of the common bile duct (CBD) and pulmonary metastases. Biliary drainage by ERCP was indicated.

Papilla had tumoral signs of infiltration. Cannulation was not achieved after several attempts with a papillotome. We accessed the distal CBD after performing a pre-cut, but the guidewire could not pass deeply. After replacing the duodenoscope with a linear echoendoscope with the intention of performing biliary drainage guided by EUS, a 10 mm duodenal perforation (type I, Stapfer) was visualized in the posterior wall of the duodenal bulb (Fig. 1A), surely caused by the tip of
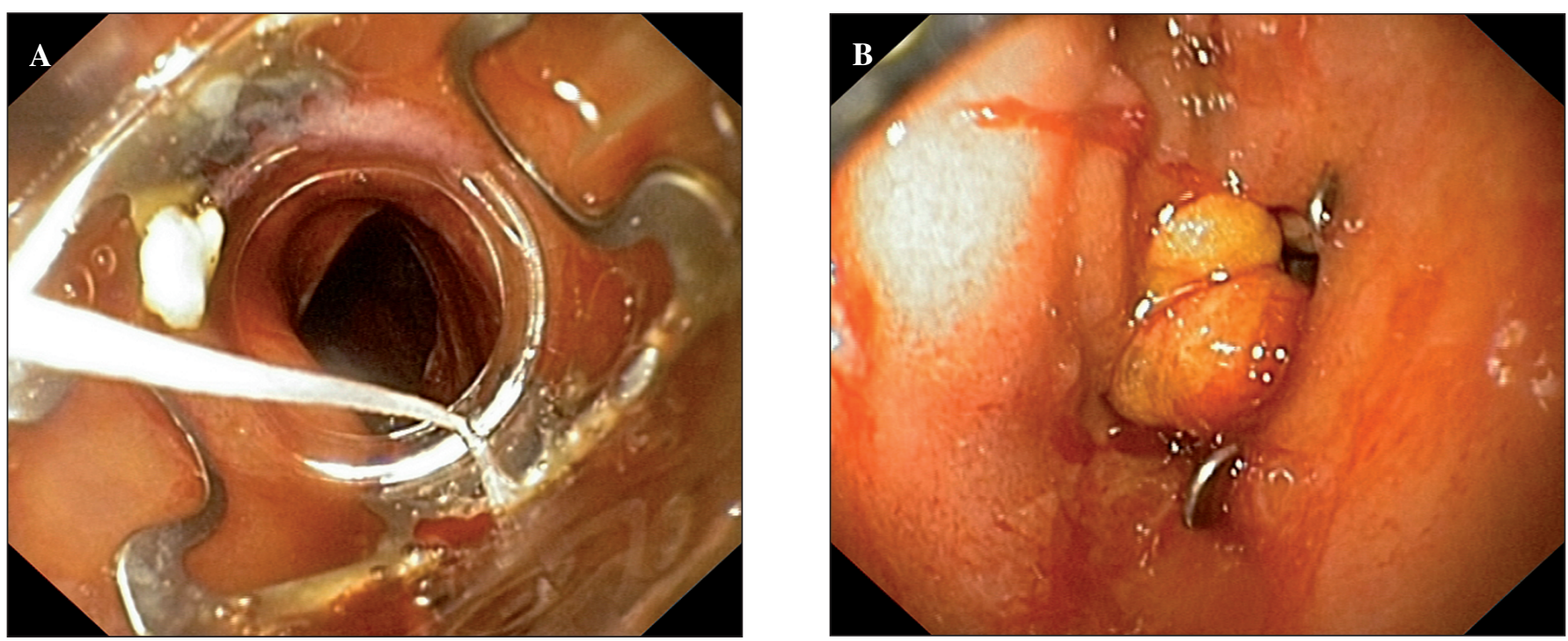

Fig. 1. A. Duodenal perforation during biliary drainage guided by EUS. B. Endoscopic closure using an over-the-scope clip (OTSC). 

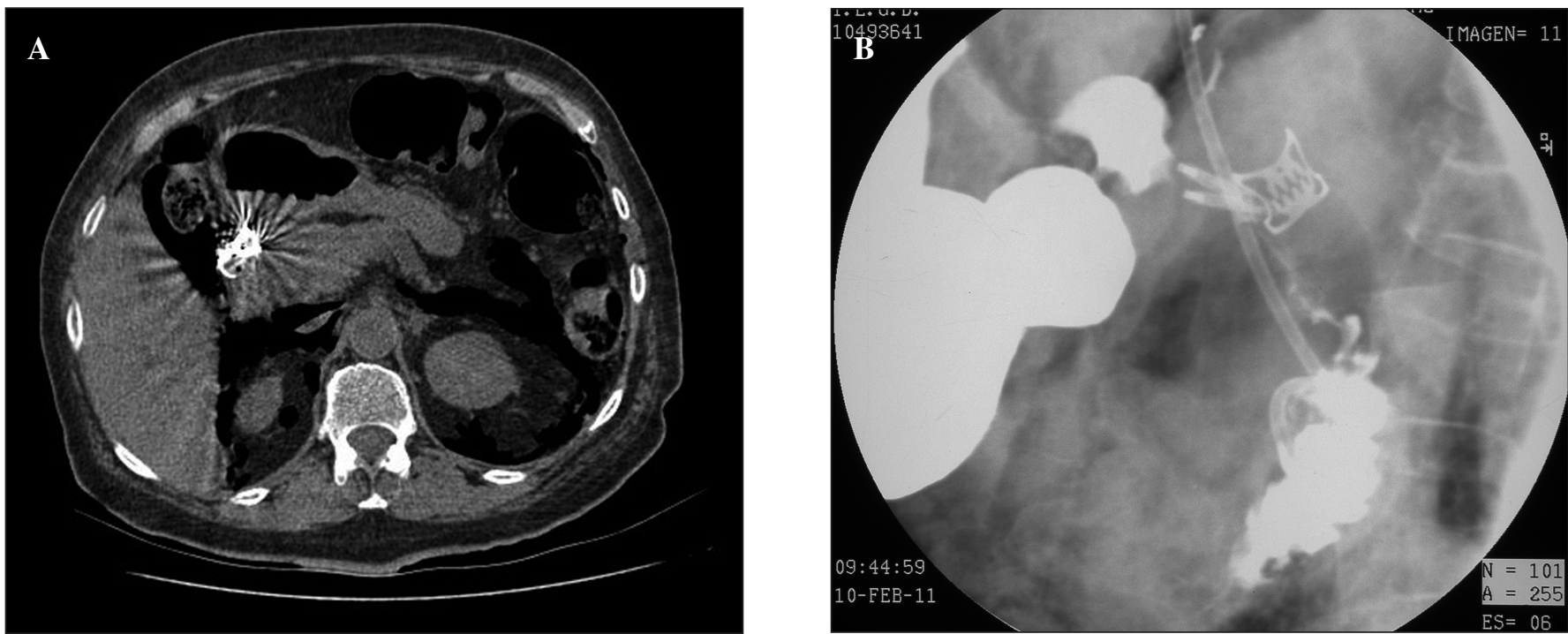

Fig. 2. A. CT scan shows the OTSC in place, air in retroperitoneum, and no free intraperitoneal fluid. B. Gastrointestinal transit reveals complete sealing of duodenal perforation.

the echoendoscope. An OTSC atraumatic clip (9.5-11 mm) was deployed with successful closure of the perforation (Fig. 1B). Two endoclips were applied in a margin to ensure complete sealing.

An immediate abdominal CT reported air in retroperitoneum without free fluid (Fig. 2A). The patient was maintained on absolute diet and received antibiotics. Gastrointestinal transit at 5 days showed no extraluminal leakage (Fig. 2 B). Oral feeding was restarted on day 6 and biliary drainage was performed by PTC.

\section{DISCUSSION}

The risk of duodenal perforation may be increased in cases of tumor infiltration and passage of an echoendoscope. The use of these OTSC clips is limited in duodenum; however, there are reports in animal models (2) and clinical case series (35) supporting its efficacy. We believe that OTSC clips are useful in the closure of duodenal perforations caused by interventional endoscopy.

\section{REFERENCES}

1. Stapfer M, Selby RR, Stain SC, Katkhouda N, Parekh D, Jabbour N, et al. Management of duodenal perforation after endoscopic retrograde cholangiopancreatography and sphincterotomy. Ann Surg 2000;232: 191-8.

2. von Renteln D, Rudolph HU, Schmidt A, Vassiliou MC, Caca K. Endoscopic closure of duodenal perforations by using an over-the-scope clip: a randomized, controlled porcine study. Gastrointest Endosc 2010;71:131-8.

3. Parodi A, Repici A, Pedroni A, Blanchi S, Conio M. Endoscopic management of GI perforations with a new over-the-scope clip device (with videos). Gastrointest Endosc 2010;72:881-6.

4. Junquera F, Martínez- Bauer E, Miquel M, Fort M, Gallach M, Brullet e, et al. OVESCO: a promising system for endoscopic closure of gastrointestinal tract perforations. Gastroenterol Hepatol 2011;34:568-72.

5. Sebastian S, Byrne AT, Torreggiani WC, Buckley M. Endoscopic closure of iatrogenic duodenal perforation during endoscopic ultrasound. Endoscopy 2004;36:245. 